\title{
Anxiety and depression among caregivers of hemodialysis patients at the Indonesian national referral hospital
}

\author{
Lucky A. Bawazier, ${ }^{1}$ Ignatius Stanley, ${ }^{2}$ Wicensius Sianipar, ${ }^{2}$ Suhardjono ${ }^{1}$
}

${ }^{1}$ Department of Internal Medicine, Faculty of Medicine, Universitas Indonesia, Cipto Mangunkusumo Hospital, Jakarta, Indonesia ${ }^{2}$ Jakarta Medical Center Hospital, Jakarta, Indonesia

\section{ABSTRACT}

Background: In Indonesia, chronic kidney disease (CKD) is primarily managed by hemodialysis (HD) because limited resources rule out the possibility of renal transplantation. HD patients are commonly accompanied by caregivers. However, most studies have neglected the health of caregivers, who play an important role in the survival of HD patients. This study aimed to determine the proportion of caregivers who suffer from anxiety and depression and the factors involved.

Methods: This was a cross-sectional study involving 100 caregivers in the HD unit of Cipto Mangunkusumo Hospital, Jakarta. This study used the hospital anxiety depression scale (HADS) to determine the extent of anxiety and depression among caregivers. All caregivers were asked to fill out the questionnaire without assistance.

Results: A total of $28 \%$ and $18 \%$ of caregivers were found to be anxious and depressed respectively. The caregiver's relationship with the patient, whether the caregiver was being paid or unpaid, the total duration of care, and income were not associated with levels of anxiety and depression. However, the proportion of each 24-hour period spent on care was significantly associated with anxiety $(\mathrm{p}=0.037)$ and depression $(\mathrm{p}=0.015)$. The time spent on care every 24 hours was also a significant predictor of anxiety $(\mathrm{p}=<0.001)$ and depression $(\mathrm{p}=0.021)$.

Conclusion: One-third of caregivers were found to be anxious and/or depressed. The time spent on care every 24 hours was a strong predictor of both anxiety and depression.

Keywords: anxiety, caregiver, chronic kidney disease, depression, hemodialysis, HADS

pISSN: 0853-1773• eISSN: 2252-8083• https://doi.org/10.13181/mji.v27i4.2999 • Med J Indones. 2018;27:271-8

- Received 17 Jul 2018• Accepted 30 Nov 2018

Corresponding author: Lucky A. Bawazier

tyasretno77@yahoo.co.id

Copyright @ 2018 Authors. This is an open access article distributed under the terms of the Creative Commons Attribution-NonCommercial 4.0 International License (http://creativecommons.org/licenses/by-nc/4.0/), which permits unrestricted non-commercial use, distribution, and reproduction in any medium, provided the original author and source are properly cited. 
The World Health Organization's (WHO) global status report on non-communicable diseases (NCDs) in 2014 identified NCDs as the leading cause of death in the world, affecting 38 million people $(68 \%)$ and causing 56 million deaths worldwide. ${ }^{1} \mathrm{~A}$ progress report issued by the WHO in 2017 revealed that $73 \%$ of deaths were due to NCDs and $27 \%$ of them were premature, including those due to chronic kidney disease. ${ }^{2}$ In Indonesia, the management of end-stage renal disease (ESRD) is mostly by hemodialysis (HD), instead of kidney transplantation due to limited resources and access. ${ }^{3} \mathrm{HD}$ patients are commonly accompanied by caregivers who also take care of them outside the HD center. Previous studies have reported that a caregiver does not have to be related to the patient and may be paid or unpaid. Caregivers are the persons who are closest to the patients in daily life. Their jobs may include reminding patients to take care of administrative tasks before HD, reminding patients to take their medications, making doctors' appointments, taking care of patients' hygiene, monitoring the foods or drinks consumed by patients, and accompanying them to the HD center. ${ }^{4}$ Although the number of studies related to the mental health condition of caregivers of HD patients continues to grow, there are still few studies that investigate the rates of anxiety and depression among caregivers in the process of taking care of HD patients over a long period of time. While several studies have reported the high prevalence of anxiety and depression among HD patients, ${ }^{5-7}$ the fact that the mental health of caregivers can also be affected has not received appropriate attention. Even when it comes to ESRD patients, previous studies have concentrated mostly on the survival and mental status of the patients but not the health and mental status of caregivers. It has been shown in a different population that being a long-term caregiver is a risk factor for depression and an increased risk of cardiovascular events. ${ }^{8,9}$ The objective of this study was to determine the mental health condition of caregivers who routinely take care of HD patients in Cipto Mangunkusumo Hospital, Jakarta.

\section{METHODS}

\section{Study design and population}

This was a cross-sectional study conducted at Cipto Mangunkusumo Hospital's HD unit. The inclusion criteria were: aged $\geq 18$ years, working as caregivers for at least 3 months, and an HD frequency of twice a week. Subjects with self-reported histories of depression, anxiety, or other psychiatric disorders were excluded from the study. A total of 100 subjects agreed to participate and were included in this study. Every subject was provided with information regarding the study and informed consent was obtained. The study was approved by the Health Research Ethics Committee, Faculty of Medicine, Universitas Indonesia-Cipto Mangunkusumo Hospital (No. 0120/UN2.F1/ETIK/2018).

\section{Anxiety and depression screening questionnaire}

The hospital anxiety and depression scale (HADS), chosen for its simplicity, was used to screen caregivers with anxiety and/or depression. It consists of a total of 14 questions with 7 questions each related to anxiety and depression. The HADS consist of questions about activities of daily living. Each caregiver was briefed on the aim of the study and how to fill out the questionnaire. All caregivers who agreed to participate were asked to fill out the questionnaire by themselves, without intervention. The HADS results were divided into 3 categories-normal (0-7), borderline (8-10), and abnormal (11-21). HADS questionnaire is used to screen patients with possibility of anxiety and/or depression but the diagnosis should be made only by psychiatrists or psychosomatic physicians according to Diagnosis and Statistical Manual of Mental Disorders (DSM5). However, subjects with borderline scores (who tended to be depressed and/or anxious) were categorized as abnormal depending on the clinical importance of their condition. Caregivers with abnormal HADS scores were advised to visit a psychiatrist and/or psychosomatic physician for further workup and possible treatment.

\section{Research variables}

The baseline characteristics comprised age, sex, educational background, marital status, HD duration, mobility of patients, duration of caring for the patients, time spent on care every 24 hours (at home and in the HD unit), caregivers' relationships with patients, whether or not they were paid for their services, caregivers' average income, patients' average income, and reason for initiating HD. On the basis of age, caregivers were divided into 3 groups: younger than 40,41-60, and 
older than 60 years. Educational background was divided into primary school, junior high school, senior high school, diploma/undergraduate, and postgraduate. The duration of HD undergone by the patient and the duration for which the caregiver had been caring for the patient were categorized into 3 time frames; 1-5 years, 6-10 years, and more than 10 years. Patients' mobility was defined in relation to whether they needed a wheelchair for everyday activities. Caregivers were categorized as related (family) or unrelated (not family) to patients. The average income of patients and caregivers was determined by using the provincial minimum wage as the baseline. The cause of initiating HD was subdivided into diabetes, hypertension, renal stone, nephrotic syndrome, and lupus nephritis.

\section{Outcomes}

The primary outcome of this study was the proportion of caregivers with depression and anxiety. The secondary outcome was the effect of the caregiver's relationship with the patient (family or unrelated), duration of being a caregiver, time spent on care every 24 hours, care giver's income, and being paid or unpaid on depression and anxiety.

\section{Statistical analysis}

Baseline characteristics were presented as frequencies and proportions (age, sex, education, marital status, HD duration, mobility of HD patients, how long the caregivers' had been caring for the patient, time spent on care every 24 hours, caregivers' relationships with patients, average income of caregivers and patients, and reason for initiating HD) as well as mean and standard deviation (SD) (age, time spent on care every 24 hours, and HD duration). The results of the HADS screening were presented as frequencies and proportions. Bivariate analyses using chi-square tests were used to determine the association between anxiety and depression and the caregiver's relationship with the patient, duration of being a caregiver, caregiver's income, status as paid or unpaid, and time spent on care every 24 hours. Continuity correction was used to determine significance. If over $20 \%$ of the expected counts were less than 5, Fisher's exact test was used to analyze the corresponding associations. Logistic regression was also performed to determine the most important variables for anxiety and depression. A p-value of $<0.05$ was considered to indicate statistical significance. The statistical analysis was conducted using Statistical Product and Service Solutions (SPSS) Statistics 23.0 (IBM Corp., Armonk, NY).

\section{RESULTS}

Table 1 provides the baseline characteristics of caregivers and HD patients at Cipto Mangunkusumo Hospital, Jakarta. The mean age of caregivers was 45.20 years (SD=13.72). The mean duration of HD treatment and caregivers' duration of care were 5.47 years $(\mathrm{SD}=6.38)$ and 5.81 years $(\mathrm{SD}=5.88)$ at home and at HD unit, respectively. The mean time spent on care every 24 hours was 9.39 hours ( $S D=6.25$ ), consisting of 4.47 hours $(\mathrm{SD}=6.20)$ and 4.92 hours $(\mathrm{SD}=0.65)$ at home and in the HD unit, respectively. Most caregivers were female (70\%). Of all 100 caregivers, $74 \%$ had university degrees, $36 \%$ held diplomas/undergraduate degrees, and 38\% had postgraduate degrees. The majority (75\%) of caregivers were married and related (94\%) to the HD patients they cared for. Almost all (81\%) HD patients were independent in terms of daily mobility (not wheelchair dependent). Almost all $(91 \%)$ caregivers were not professionally paid to care for the patient and some (28\%) had average incomes lower than the provincial minimum wage. This was in line with the average HD patient's income, which was (35\%) lower than the provincial minimum wage. The most common cause of kidney disease observed in this study was hypertension (52\%).

Table 2 describes the frequency of anxiety and depression found among caregivers of HD patients at Cipto Mangunkusumo Hospital. Of the 100 caregivers, almost one-third were anxious and/or depressed, according to the results of the HADS questionnaire. The mean HADS anxiety dimension score was 5.17 (SD=3.67), whereas the mean HADS depression dimension score was 4.01 $(S D=3.29)$.

Table 3 describes the relationship between the analyzed covariates and anxiety, depression and mixed cases (anxiety and depression in the same person). Caregivers who were related to patients were more likely to have abnormal anxiety scores than those who were not related. Predictably, paid caregivers were found 
Table 1. Baseline characteristics of caregivers and HD patients $(n=100)$

\begin{tabular}{|c|c|}
\hline Characteristics & $\%$ \\
\hline \multicolumn{2}{|l|}{ Age } \\
\hline$<40$ & 26 \\
\hline $41-60$ & 60 \\
\hline$>60$ & 14 \\
\hline \multicolumn{2}{|l|}{ Sex } \\
\hline Male & 30 \\
\hline Female & 70 \\
\hline \multicolumn{2}{|l|}{ Education level } \\
\hline Primary school & 2 \\
\hline Junior high school & 9 \\
\hline Senior high school & 15 \\
\hline Diploma/undergraduate & 36 \\
\hline Postgraduate & 38 \\
\hline \multicolumn{2}{|l|}{ Marital status } \\
\hline Unmarried & 21 \\
\hline Married & 75 \\
\hline Widow & 4 \\
\hline \multicolumn{2}{|l|}{ Patients' HD duration (years) } \\
\hline $1-5$ & 68 \\
\hline $6-10$ & 17 \\
\hline$>10$ & 15 \\
\hline \multicolumn{2}{|l|}{ HD patients' mobility } \\
\hline Independent & 81 \\
\hline Wheelchair dependent & 19 \\
\hline \multicolumn{2}{|c|}{$\begin{array}{l}\text { Caregivers' duration of caring for patients } \\
\text { (years) }\end{array}$} \\
\hline $1-5$ & 61 \\
\hline $6-10$ & 21 \\
\hline$>10$ & 18 \\
\hline \multicolumn{2}{|c|}{ Time spent on care every 24 hours } \\
\hline \multicolumn{2}{|l|}{ At home } \\
\hline$<4$ hours & 70 \\
\hline$\geq 4$ hours & 30 \\
\hline \multicolumn{2}{|l|}{ At HD center } \\
\hline$<4$ hours & 5 \\
\hline$\geq 4$ hours & 95 \\
\hline \multicolumn{2}{|l|}{ At home \& HD center } \\
\hline$<9$ hours & 71 \\
\hline$\geq 9$ hours & 29 \\
\hline \multicolumn{2}{|c|}{ Caregivers' relationship with patients } \\
\hline Not related & 6 \\
\hline Related & 94 \\
\hline \multicolumn{2}{|l|}{ Paid as a caregiver } \\
\hline Unpaid & 91 \\
\hline Paid & 9 \\
\hline
\end{tabular}

Table 1. Baseline characteristics of caregivers and HD patients $(n=100)$ (continued)

\begin{tabular}{|lc}
\hline Average income of caregivers & \\
\hline Less than provincial minimum wage & 28 \\
\hline Same as provincial minimum wage & 12 \\
\hline More than provincial minimum wage & 22 \\
\hline Average income of HD patients & \\
\hline Less than provincial minimum wage & 35 \\
\hline Same as provincial minimum wage & 10 \\
\hline More than provincial minimum wage & 17 \\
\hline Etiology of CKD & \\
\hline Diabetes & 32 \\
\hline Hypertension & 52 \\
\hline Renal stone & 3 \\
\hline Nephrotic syndrome & 7 \\
\hline Lupus nephritis & 2 \\
\hline Others & 4 \\
\hline
\end{tabular}

$\mathrm{HD}=$ hemodialysis; $\mathrm{CKD}=$ chronic kidney disease

Table 2. Anxiety and depression among caregivers of HD patients

\begin{tabular}{lcc}
\hline Caregiver anxiety and depression & $\%$ & CI 95\% \\
\hline Anxiety & 28 & $(14-31)$ \\
Depression & 18 & $(7-20)$ \\
Mixed case* $^{*}$ & 12 & $(6-19)$ \\
\hline
\end{tabular}

*mixed case consisted of subjects with both anxiety and depression

to be less anxious than those who were unpaid. Those who had provided care for less than 4 years were found to be more anxious than those who had been caring for patients for more than 4 years, and the time spent on care every 24 hours both at home and in the HD unit significantly affected the anxiety dimension of the HADS score $(p=0.037)$. Caregivers' income was also found to affect the score, especially so in those who had an income lower than the minimum provincial wage, although this relationship was not significant.

Related caregivers were more likely than unrelated caregivers to have depression scores in the abnormal range. As was the case with anxiety, unpaid caregivers were also more likely to have abnormal depression scores. However, in terms of the duration of care, those who had been caregivers for in excess of 4 years had higher abnormal depression scores than 
Table 3. Bivariate relationship and logistic regression analysis between HADS scores and covariates

\begin{tabular}{|c|c|c|c|c|c|c|c|}
\hline \multirow{2}{*}{ Covariates } & \multicolumn{7}{|c|}{ HADS anxiety score } \\
\hline & Normal & Abnormal & $\mathrm{p}$ & OR $(95 \% \mathrm{CI})$ & B & $\mathrm{p}$ & $\begin{array}{l}\text { Adjusted } \\
\text { OR }\end{array}$ \\
\hline \multicolumn{8}{|l|}{ Relationship with the patient } \\
\hline Related & $66(70.21 \%)$ & $28(29.79 \%)$ & \multirow{2}{*}{$0.181^{*}$} & 1.42 & \multirow{2}{*}{2.067} & \multirow{2}{*}{0.999} & \multirow{2}{*}{0.110} \\
\hline Not related & $6(100 \%)$ & $0(0 \%)$ & & $(1.25-1.63)$ & & & \\
\hline \multicolumn{8}{|l|}{ Paid as a caregiver } \\
\hline Unpaid & $65(71.43 \%)$ & $26(28.57 \%)$ & \multirow{2}{*}{$1.000^{*}$} & 1.40 & \multirow{2}{*}{0.792} & \multirow{2}{*}{0.479} & \multirow{2}{*}{2.208} \\
\hline Paid & $7(77.77 \%)$ & $2(22.23 \%)$ & & $(0.23-7.19)$ & & & \\
\hline \multicolumn{8}{|l|}{ Caregiver duration of care } \\
\hline$<4$ years & $31(65.95 \%)$ & $16(34.05 \%)$ & \multirow{2}{*}{$0.296^{+}$} & 0.57 & \multirow{2}{*}{-0.322} & \multirow{2}{*}{0.586} & \multirow{2}{*}{0.724} \\
\hline$\geq 4$ years & $41(77.36 \%)$ & $12(22.64 \%)$ & & $(0.24-1.37)$ & & & \\
\hline \multicolumn{8}{|l|}{ Caregiver income } \\
\hline$<\mathrm{MPW}$ & $37(71.15 \%)$ & $15(28.85 \%)$ & \multirow{2}{*}{$0.326^{\dagger}$} & 0.52 & \multirow{2}{*}{-1.012} & \multirow{2}{*}{0.145} & \multirow{2}{*}{0.363} \\
\hline$\geq \mathrm{MPW}$ & $20(80 \%)$ & $5(20 \%)$ & & $(0.19-1.47)$ & & & \\
\hline \multirow{2}{*}{$\begin{array}{l}\text { Time spent on care every } 24 \text { hours } \\
\text { (at home and in the HD unit) }\end{array}$} & $72(72 \%)$ & 28 (28\%) & $0.037^{\ddagger}$ & 1.39 & 2.048 & 0.001 & 7.755 \\
\hline & \multicolumn{7}{|c|}{ HADS depression score } \\
\hline Relationship with the patient & & & & & & & \\
\hline Related & $77(81.91 \%)$ & $17(18.09 \%)$ & $1000 *$ & 1.10 & 0031 & 0980 & 1032 \\
\hline Not related & $5(83.33 \%)$ & $1(16.67 \%)$ & 1.000 & $(0.12-10.06)$ & 0.001 & 0.700 & 1.002 \\
\hline Paid as a caregiver & & & & & & & \\
\hline Unpaid & $75(82.41 \%)$ & $16(17.59 \%)$ & $0662 *$ & 0.75 & 0172 & 0971 & 0912 \\
\hline Paid & $7(77.78 \%)$ & $2(22.22 \%)$ & 0.005 & $(0.14-3.93)$ & $-0.1 / 3$ & 0.071 & 0.042 \\
\hline Caregiver duration of care & & & & & & & \\
\hline$<4$ years & $41(87.23 \%)$ & $6(12.77 \%)$ & $03077^{\dagger}$ & 2.00 & 0972 & 0147 & 0278 \\
\hline$\geq 4$ years & $41(77.36 \%)$ & $12(22.64 \%)$ & - & $(0.69-5.84)$ & (.8. & 0.117 & 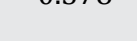 \\
\hline Caregiver income & & & & & & & \\
\hline$<\mathrm{MPW}$ & $44(84.61 \%)$ & $8(15.39 \%)$ & $0429^{+}$ & 0.48 & -0234 & 0759 & 0792 \\
\hline$\geq \mathrm{MPW}$ & $22(88 \%)$ & $1(12 \%)$ & 0.723 & $(0.13-1.78)$ & T. & נינה 0. & 0.172 \\
\hline Time spent on care every 24 hours & $82(82 \%)$ & $18(18 \%)$ & $\mathbf{0 . 0 1 5}^{\dagger}$ & $(0.00-0.03)$ & 1.560 & 0.021 & 4.760 \\
\hline & & & HAD & nixed score & & & \\
\hline Relationship with the patient & & & & & & & \\
\hline Related & $81(83.33 \%)$ & $8(16.67 \%)$ & $1000 *$ & 1.15 & 1055 & 0000 & 0210 \\
\hline Not related & $6(81.91 \%)$ & $0(18.09 \%)$ & 1.000 & $(1.06-1.24)$ & 1.955 & 0.999 & 0.310 \\
\hline Paid as a caregiver & & & & & & & \\
\hline Unpaid & $79(82.41 \%)$ & 7 (17.59\%) & $100 \Omega *$ & 1.10 & 0295 & 0814 & 134 \\
\hline Paid & $8(77.78 \%)$ & $1(22.22 \%)$ & 1.000 & $(0.13-9.66)$ & J & 0.017 & $1.0 \mathrm{~T}$ \\
\hline Caregiver duration of care & & & & & & & \\
\hline$<4$ years & $43(87.23 \%)$ & $2(12.77 \%)$ & $0107+$ & 1.91 & 0025 & 0191 & 0206 \\
\hline$\geq 4$ years & $44(77.36 \%)$ & $6(22.64 \%)$ & $0.482^{\prime}$ & $(0.54-6.81)$ & $-0.9<5$ & 0.184 & 0.396 \\
\hline Caregiver income & & & & & & & \\
\hline$<\mathrm{MPW}$ & $46(84.61 \%)$ & $4(15.39 \%)$ & $0470 *$ & 0.52 & 0073 & 0928 & 1076 \\
\hline$\geq \mathrm{MPW}$ & $22(88 \%)$ & $2(12 \%)$ & . & $(0.12-2.34)$ & S & 0.720 & 1.070 \\
\hline $\begin{array}{l}\text { Time spent on care every } 24 \text { hours } \\
\text { (at home and in the HD unit) }\end{array}$ & $92(82 \%)$ & $8(18 \%)$ & $0.049^{\ddagger}$ & $\begin{array}{c}0.91 \\
(0.01-0.11)\end{array}$ & 1.681 & 0.018 & 5.373 \\
\hline
\end{tabular}

*Fisher's exact test; ${ }^{\dagger}$ Continuity correction test; ${ }^{\ddagger}$ Mann-Whitney U test. HADS=hospital anxiety and depression scale; OR=odds ratio; $\mathrm{CI}=$ confidence interval; $\mathrm{MPW}=$ minimum provincial wage; $\mathrm{HD}=$ hemodialysis 
those who had been providing care for less than 4 years. Caregivers with incomes lower than the minimum provincial wage also had higher depression scores. Caregivers' time spent on care every 24 hours both at home and in the HD unit significantly affected the depression scores $(p=0.015)$. Furthermore, there were more mixed cases among related caregivers than among those who were not related to the patients they cared for. A similar result was observed in unpaid caregivers. There were also more mixed cases among caregivers who had provided more than 4 years of care than among those who had been caring for patients for less than 4 years. A higher proportion of mixed cases was also found in caregivers with a salary below the provincial minimum wage. Caregivers' time spent on care every 24 hours both at home and in the HD unit was significantly associated with both anxiety and depression $(\mathrm{p}=0.049)$.

The logistic regression analysis that used to predict the effects of several covariates on anxiety, depression, and mixed cases were also shown in table 3 . In terms of the relation between anxiety, depression, or mixed cases and several covariates such as the relationship with the patient, being paid or unpaid, duration of care, and caregivers' income, these covariates were not strong predictors. Interestingly, time spent on care every 24 hours was a significant predictor of anxiety ( $\mathrm{p}=0.001 ; \mathrm{B}: 2.048,0 \mathrm{R}: 7.755)$, depression $(\mathrm{p}=0.021 ; \mathrm{B}: 1.560, \mathrm{OR}: 4.760)$, and mixed cases $(p=0.018$; B: 1.681, OR: 5.373).

\section{DISCUSSION}

Many previous studies have focused on assessing the burden of caring for someone undergoing HD, but have neglected anxiety and depression among caregivers. The objectives of this study are to determine the characteristics of HD caregivers, the association of those characteristics with several covariates, and whether those covariates could become predictors of anxiety and depression or not. Our study showed that the mean age of caregivers was 45.20 years, which was similar to the mean ages reported in prior studies. ${ }^{10,11}$ Most of the HD caregivers in our study were female, similar to studies in India and China. ${ }^{12,13} \mathrm{HD}$ patients and their caregivers in this study were mostly related, similar to other studies. ${ }^{14-16}$ In our study, this could be explained by the fact that most subjects were married Indonesian women, who tend to be housewives and therefore have more time to care for their family members. The proportions of caregivers with undergraduate and postgraduate degrees were higher than the proportion with only primary or high school degrees. This was similar to findings from previous studies conducted in developed countries. ${ }^{17,18}$ This study found that $28 \%$ and $18 \%$ of caregivers were anxious and depressed, respectively. These results are higher than those reported for the general population in 2017 by the WHO, i.e. $4.4 \%$ and $3.6 \%$ for anxiety and depression respectively. ${ }^{19}$ Furthermore, an earlier study reported higher percentage (42.6\%) of caregivers with HADS depression scores in the abnormal range. ${ }^{20}$ Another study, by Nipp et al, ${ }^{21}$ which observed anxiety and depression using HADS in incurable cancer patients, who experience similar psychological effects to those of HD patients undergoing routine dialysis, reported a similar percentage $(16.4 \%)$ of caregivers with abnormal HADS depression scores but a higher percentage (42.2\%) of caregivers with abnormal HADS anxiety scores. The difference between our study and previous studies regarding the prevalence of anxiety and depression might be due to technical issues during data collection. Several factors might have had an impact on the HADS results in this study: these are outlined below.

Ideally, to prevent biased answers, the HADS questionnaire should not be completed while the caregivers are in close proximity to the patients, but this was not possible because the patients needed their caregivers' assistance in eating and drinking during the dialysis process. Some caregivers also needed the patients' help to understand the questionnaire. In Indonesia, most people have strong spiritual lives related to their religion. This factor could have influenced the frequency of anxiety and depression observed in this study as they coped well with their burden. The sense of responsibility of caring for the patient, especially among those who were related, and the feeling of gratefulness for not having to suffer like the patient, had a great effect on the HADS results. This is supported by a study conducted in Iran by Rahnama et $\mathrm{al}^{22}$ which showed the coping and moderating effects of 
religion. The relationship with the patient, being paid or unpaid, total duration of care, and income did not significantly affect anxiety and depression. However, time spent on care every 24 hours both at home and in the HD unit significantly affected both anxiety and depression. In further analysis, it was shown that time spent on care every 24 hours was also a strong predictor of anxiety and depression as in Zhang et $\mathrm{al}^{23}$ study. This might be due to economic reasons, especially in patients who are not as productive as before undergoing routine HD. Therefore, caregivers whose incomes are lower than the provincial minimum wage have to carry the burden of fulfilling daily needs and caring for patients by themselves. The limitation of this study was a small sample size, further research should be conducted in larger sample size to better represent the true outcome in the population. Additionally, there might be an observer bias during filling the questionnaire because some participants needed assistance to understand the question and answer options due to low educational background.

In conclusion, our study demonstrated that the time spent on care every 24 hours is a strong predictor of anxiety and depression among HD caregivers. Therefore, the authors recommend advising all HD caregivers to institute a shift system, so that the responsibility of caring for the patient does not fall on a single person. Furthermore, it is recommended that every HD unit gather all caregivers at least once a month so that their problems can be shared and they can receive solutions and psychological support.

\section{Conflicts of interest}

The authors affirm no conflict of interest in this study.

\section{Acknowledgment}

We would like to express our gratitude to all involved staff at the hemodialysis unit of Cipto Mangunkusumo Hospital.

\section{REFERENCES}

1. Global status report on non-communicable disease. World Health Organization (WHO). 2014.

2. Non-communicable disease progress monitor. World Health Organization (WHO). 2017.

3. Situasi Penyakit Ginjal Kronis. Center of data and information Indonesian Ministry of Health. 2017.
Indonesian.

4. Suri RS, Larive B, Garg AX, Hall YN, Pierratos A, Chertow GM, et al. Burden on caregivers as perceived by hemodialysis patients in the Frequent Hemodialysis Network (FHN) trial. Nephrol Dial Transplant. 2011;26(7):2316-22.

5. Najafi A, Keihani S, Bagheri N, Jolfaei AG, Meybodi AM. Association betweenanxiety and depression with dialysis adequacy in patients on maintenance hemodialysis. Iran J Psychiatry Behav Sci. 2016;10(2):e4962.

6. Ng HJ, Tan WJ, Mooppil N, Newman S, Griva K. Prevalence and patterns of depression and anxiety in hemodialysis patients: a 12-month prospective study on incident and prevalent populations. Br J Health Psychol. 2015;20(2):374-95.

7. El Filali A, Bentata Y, Ada N, Oneib B. Depression and anxiety disorders in chronic hemodialysis patients and their quality of life: a cross-sectional study about 106 cases in the northeast of Morocco. Saudi J Kidney Dis Transpl. 2017;28(2):341-8.

8. Lee CY, Lee Y, Wang LJ, Chien CY, Fang FM, Lin PY. Depression, anxiety, quality of life, and predictors of depressive disorders in caregivers of patients with head and neck cancer: a six-month follow-up study. J Psychosom Res. 2017;100:29-34.

9. Wu KK, Bos T, Mausbach BT, Milic M, Ziegler MG, von Känel R, et al. Long-term caregiving is associated with impaired cardiovagal baroreflex. J Psychosom Res. 2017;103:29-33.

10. Shakya D, Tuladhar J, Poudel S. Burden and depression among caregivers of hemodialysis patients. Palliat Med Care. 2017;4(1):1-6.

11. Mashayekhi F, Pilevarzadeh M, Rafati F. The assessment of caregiver burden in caregivers of hemodialysis patients. Mater Sociomed. 2015;27(5):333-6.

12. Giri AP, Mohanasundaram S, Nayar PC, Sharma RN, Kurian G. Evaluation of mental health using hospital anxiety and depression scale in primary caregivers of patients undergoing dialysis. Int J Med Sci Public Health. 2016;5(9):1814-7.

13. Xie H, Cheng C, Tao Y, Zhang J, Robert D, Jia J, et al. Quality of life in Chinese family caregivers for elderly people with chronic disease. Health Qual Life Outcomes. 2016;14:99.

14. Bayoumi MM. Subjective burden on family carers of hemodialysis patients. Open J Nephrol. 2014;4(2):79-85.

15. Belasco A, Barbosa D, Bettencourt AR, Diccini S, Sesso R. Quality of life of family caregivers of elderly patients on hemodialysis and peritoneal dialysis. Am J Kidney Dis. 2006;48(6):955-63.

16. Sajadi SA, Ebadi A, Moradian ST. Quality of life among family caregivers of patients on hemodialysis and its relevant factors: a systematic review. Int J Community Based Nurs Midwifery. 2017;5(3):206-18.

17. Rioux JP, Narayanan R, Chan CT. Caregiver burden among nocturnal home hemodialysis patients. Hemodial Int. 2012;16(2):214-9.

18. Farahani MA, Ghane G, Sydfatemi N, Hagani H. Effect of educational program on the burden of family caregivers of hemodialysis patients. Evidence Based Care Journal. 2016;6(1):7-18.

19. Depression and other common mental disorders: global health estimates. World Health Organization. 2017. 
20. Avşar U, Avşar UZ, Cansever Z, Yucel A, Cankaya E, Certez $\mathrm{H}$, et al. Caregiver burden, anxiety, depression, and sleep quality diffreneces in caregivers of hemodialysis patients compared with renal transplant patients. Transplant Proc. 2015;47(5):1388-91.

21. Nipp RD, El-Jawahri A, Fishbein JN, Gallagher ER, Stagl JM, Park ER, et al. Factors associated with depression and anxiety symptoms in family caregivers of patients with incurable cancer. Ann Oncol. 2016;27(8):1607-12.
22. Rahnama P, Javidan AN, Saberi H, Montazeri A, Tavakkoli $\mathrm{S}$, Pakpour AH, et al. Does religious coping and spirituality have a moderating role on depression and anxiety in patients with spinal cord injury? a study from Iran. Spinal Cord. 2015;53(12):870-4.

23. Zhang R, Cui X, Zhuang H, Xie W, Iv L, Liu Y, et al. The burden for caring patients on maintenance hemodialysis is influenced by social and demographic factors. Gen Med. 2016;4:281. 